\title{
Research on the Influence of Perceived Interest on Digital Textbook Learning Motivation
}

\author{
Kyung A Jin \\ Department of Multimedia Design, Korea Art College, Seoul, 120-837, Korea \\ jin_ka@naver.com
}

\begin{abstract}
The purpose of this study is to understand how the Digital Textbook interface developed in the leading researches affects learner's motivation. As a result, four out of seven interest factor of Digital textbook interface affect learning motivation. These interest factors are emphatic factor, esthetic factor, explorative factor, and cognitive factor. Experimental factor also is proven to be a potential influential factor. The leading researches proved that most of interest factors have a meaningful effect on learning motivation. Therefore, the interest factors supplied in the Digital Textbook user interface confirmed its education value.
\end{abstract}

Keywords: Digital Textbook, Interest factor, ARCS Learning Motivation

\section{Introduction}

This research is a beginning of a process that will increase the educational effect and the satisfaction of Digital Textbook users. The purpose of the research is to prove that the interest factors of Digital text book user interface affect learning motivation. This research is based on the leading project ${ }^{1}$ that structured the interesting factors of Digital interface and ought to prove the influence of perceived interest of the learner on learning motivation. These different approaches of the research are to confirm the significant educational value of the seven interest factors that the leading researches structure.

\section{Logical Background}

\subsection{Interest Logic}

Concerning the structuralized process of interest factor, the research has leaned on the logics of modern interest philosophers such as Herbart and Dewey. When it came to building a analysis of interest categories, Multifaceted Interest of Herbart became the center logic. The seven interest factors that the researches structured include personal inner factor and outer situational factor and are experimental, emphatic, esthetic, operative, explorative, social and cognitive factor. These factors reflect on interest concept of Herbart that interest is a combination of all of our knowledge and emotion. 


\subsection{Learning Motivation Theory}

In order to measure learning motivation, it used ARCS learning motivation model 2 of Keller. ARCS model that Keller suggest defines motivation into the observable direction and intensity according to four factors of attention, relativity, confidence and satisfaction.

\section{Research Range and Method}

\subsection{Survey}

The range of research is a total of 520 students in Guil elementary school and Wolgye middle school in Seoul. The survey was divided into a pre-survey and a actual survey. 100 students of the elementary and the middle school took the pre-survey in order to examine errors, validity, and credibility of the survey questions. The survey started on March 27th, 2012 and ended on April 5th, 2012.

\subsection{Statistic Data Analysis}

In this research, it ought to examine a correlation between learning motivation and perceived interest of Digital Textbook UI user. It uses the following method in order to analyze the collected survey data.

For statistic process of the research, this research used SPSSWIN 18.0 and the data was proved with a significance level, $\mathrm{p}<0.05$. At first, it accomplished a frequency analysis in order to understand a personal characteristic factor of an individual respondent. At second, it accomplished Promax Rotation factorial analysis in order to draw key elements needed to realize interesting factors to user interface of Digital Textbook. It also used AMOS to analyze confirmatory factors and examined the model suitability of the analyzed factors. At third, it accomplished credibility analysis using Cronbach's $\alpha$ in order to measure the inner suitability of measurement tool used in this research. At fourth, it accomplished correlation analysis in order to understand a correlation between the interest factor and learning motivation of each respondent. Lastly, it accomplished a multiple regression analysis in order to understand the influence of interest factors on learning motivation.

\section{Research Result}

\subsection{Correlation per factors}

In order to understand a correlation between interest factor and an individual respondent, the research accomplished person correlation analysis. As a result $\langle$ Table 1 $\rangle$, it turned out that there are meaningful correlation between a respondent and the entire interesting factor within the significant level of 0.05 . 
Examining the overall correlations between interest factors and factors of learning motivation, the correlation factors for attention, confidence, relativity, and satisfactory are $\mathrm{r}=0.54(\mathrm{p}<0.05), \quad \mathrm{r}=0.49(\mathrm{p}<0.05), \quad \mathrm{r}=0.50(\mathrm{p}<0.05)$, and $\mathrm{r}=0.53(\mathrm{p}<0.05)$ respectively. This shows a high correlation between learning motivation and overall interest factors.

Examining the overall correlations between interest factors and sub-factor of learning motivation, all of sub factors that are experimental, inquiring, and cognitive showed a high correlation between the interest factors with a correlation factor of $r=0.48$. The esthetic factor showed a correlation factor of $r=0.45$. The relative and social factor showed $r=0.42 \mathrm{sub}$ and the operant factor showed $\mathrm{r}=0.38$.

When the correlation results per respondent of the survey were combined, the experimental, explorative, and cognitive factors showed the strongest correlation with learning motivation. The esthetic, emphatic, and social factors were followed and lastly, operative showed some correlation. The analysis of correlation showed that the higher user interest on Digital Textbook UI would lead to higher learning motivation.

Table 1. Correlation between respondent and interest factors

\begin{tabular}{|c|c|c|c|c|c|c|c|c|c|c|c|c|c|}
\hline & $\begin{array}{l}\text { Interest } \\
\text { Factor }\end{array}$ & $\begin{array}{l}\text { xperimen } \\
\text { Factor }\end{array}$ & $\begin{array}{l}\text { Emphatic } \\
\text { Factor }\end{array}$ & $\begin{array}{l}\text { Esthetic } \\
\text { Factor }\end{array}$ & $\begin{array}{l}\text { Operativ } \\
\text { Factor }\end{array}$ & $\begin{array}{l}\text { Explorativ } \\
\text { Factor }\end{array}$ & $\begin{array}{l}\text { eSocialc } \\
\text { Factor }\end{array}$ & $\begin{array}{l}\text { Cognitiv } \\
\text { Factor }\end{array}$ & $\begin{array}{l}\text { e Learning } \\
\text { Motivation }\end{array}$ & Attention & Confidenc & Relativitys & Satisfactory \\
\hline $\begin{array}{l}\text { Interest } \\
\text { Factor }\end{array}$ & 1 & & & & & & & & & & & & \\
\hline $\begin{array}{l}\text { Experimental } \\
\text { Factor }\end{array}$ & $1.87^{*}$ & 1 & & & & & & & & & & & \\
\hline $\begin{array}{l}\text { Emphatic } \\
\text { Factor }\end{array}$ & $.63^{*}$ & $.54^{*}$ & 1 & & & & & & & & & & \\
\hline $\begin{array}{l}\text { Esthetic } \\
\text { Factor }\end{array}$ & $.83^{*}$ & $.61^{*}$ & $.48^{*}$ & 1 & & & & & & & & & \\
\hline $\begin{array}{l}\text { Operative } \\
\text { Factor }\end{array}$ & $.72^{*}$ & $.55^{*}$ & $.35^{*}$ & $.60^{*}$ & 1 & & & & & & & & \\
\hline $\begin{array}{l}\text { Explorative } \\
\text { Factor }\end{array}$ & $.87^{*}$ & $.73^{*}$ & $.48^{*}$ & $.63^{*}$ & $.65^{*}$ & 1 & & & & & & & \\
\hline Social Factor & $.80^{*}$ & $.69^{*}$ & $.54^{*}$ & $.57^{*}$ & $.49^{*}$ & $.63^{*}$ & 1 & & & & & & \\
\hline $\begin{array}{l}\text { Cognitive } \\
\text { Factor }\end{array}$ & $.85^{*}$ & $.75^{*}$ & $.48^{*}$ & $.58^{*}$ & $.56^{*}$ & $.72^{*}$ & $.68^{*}$ & 1 & & & & & \\
\hline $\begin{array}{l}\text { Learning } \\
\text { Motivation }\end{array}$ & $.55^{*}$ & $.48^{*}$ & $.42^{*}$ & $.45^{*}$ & $.38^{*}$ & $.48^{*}$ & $.42^{*}$ & $.48^{*}$ & 1 & & & & \\
\hline Attention & $.54^{*}$ & $.45^{*}$ & $.41^{*}$ & $.44^{*}$ & $.38^{*}$ & $.47^{*}$ & $.41^{*}$ & $.45^{*}$ & $.95^{*}$ & 1 & & & \\
\hline Confidence & $.49^{*}$ & $.42^{*}$ & $.36^{*}$ & $.42^{*}$ & $.31^{*}$ & $.43^{*}$ & $.34^{*}$ & $.43^{*}$ & $.90^{*}$ & $.79^{*}$ & 1 & & \\
\hline Relativity & $.50^{*}$ & $.43^{\circ}$ & $.38^{*}$ & $.39^{*}$ & $.36^{*}$ & $.43^{*}$ & $.38^{*}$ & $.44^{*}$ & $.94^{*}$ & $.85^{*}$ & $.79^{*}$ & 1 & \\
\hline Satisfaction & $.53^{*}$ & $.46^{*}$ & $.40^{*}$ & $.41^{*}$ & $.35^{*}$ & $.46^{2}$ & $.42^{*}$ & $.46^{*}$ & $.93^{*}$ & $.84^{*}$ & $.80^{*}$ & $.82^{*}$ & 1 \\
\hline
\end{tabular}

\subsection{Influence of interest factors on learning motivation}

In order to understand the influence of perceived interest of the user on learning motivation, the research accomplished Hierarchical Regression analysis that regulated the personal characteristics of the research targets. Examining the personal characteristic factor that affects the total learning motivation, the result of the analysis showed that the usage of computer affect learning motivation. In other words, as the hours of using computer lessens, there are 
more learning motivations. Also, relating to gender, girl showed more learning motivation than boys.

The influence factors of interest factor on learning motivation are cognitive factor with $\beta=.17(\mathrm{p}<.05)$, emphatic factor with $\beta=.16(\mathrm{p}<.05)$, esthetic factor with $\beta=.14(\mathrm{p}<.05)$, and explorative factor $\beta=.13(\mathrm{p}<.05)$. These four factors have a similar size of influence. Figure 1 below shows the result in a diagram.

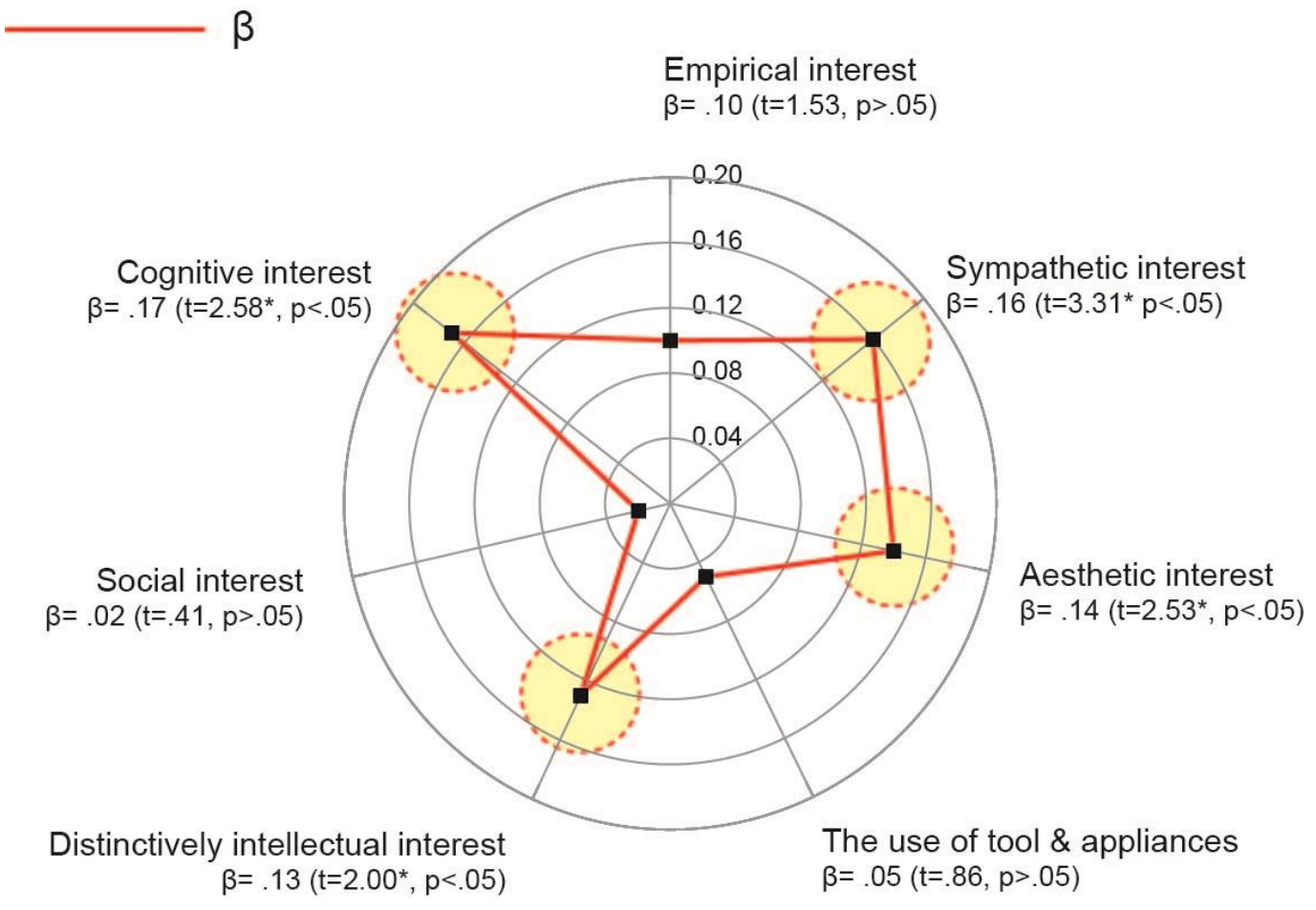

Figure 1. Influence of interest factor on learning motivation

\subsection{Influence of interest factor on attention}

Following is the result of hierarchical regression analysis on the influence of perceived interest factor on low ranked interest factor. The influence of interest factor on attention is as followed.

The level of attention increase with the emphatic, esthetic, and cognitive factors and among three factors, there was no significant difference in terms of what factor is more significant. In terms of individual learner's characteristic, the level of attention increase as the usage of computer decreased and junior high school students showed higher level of attention than student of elementary school. 


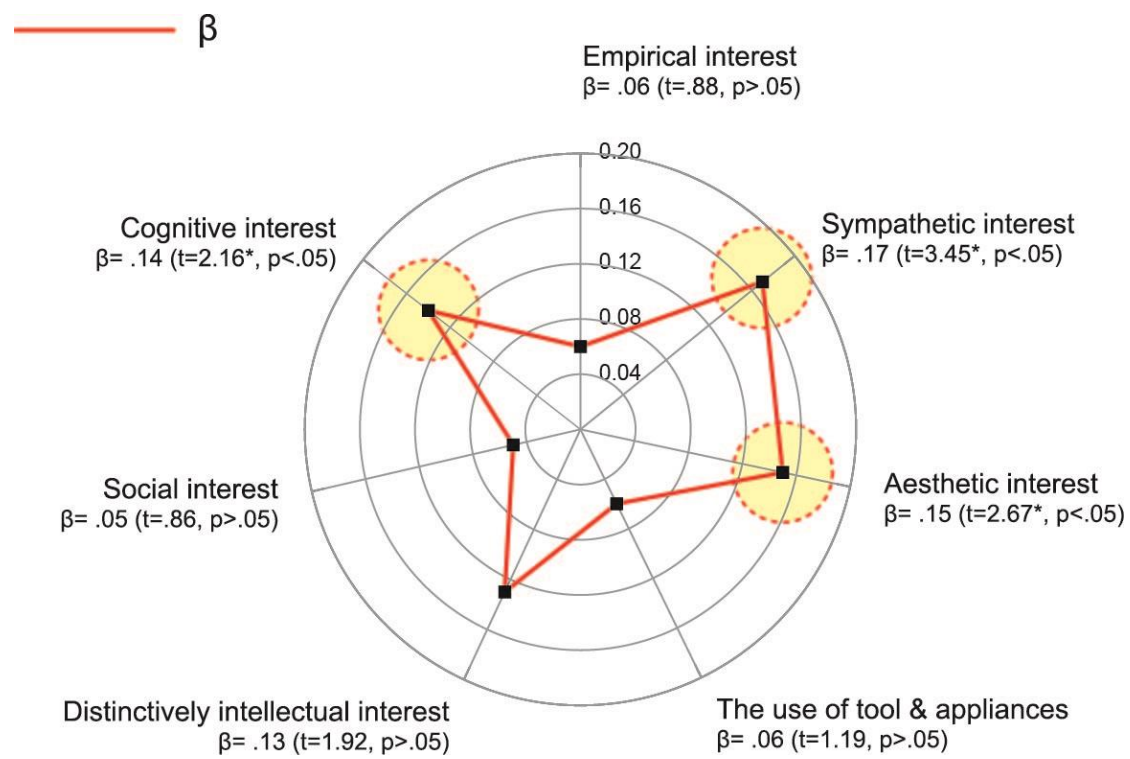

Figure 2. Influence of interest factor on attention

\subsection{Influence of interest factor on relativity}

Following is the result of hierarchical regression analysis on the influence of perceived interest factor on low ranked interest factor.

As a result, relativity increased with cognitive and emphatic factor. The experimental factor didn't appear to have a significant influence but it can be said that it has a potential possibility of being a influential factor. Examining person characteristic of learners, relativity increase as the usage of computer decreased and it also showed that students of middle school showed more relativity than elementary students.

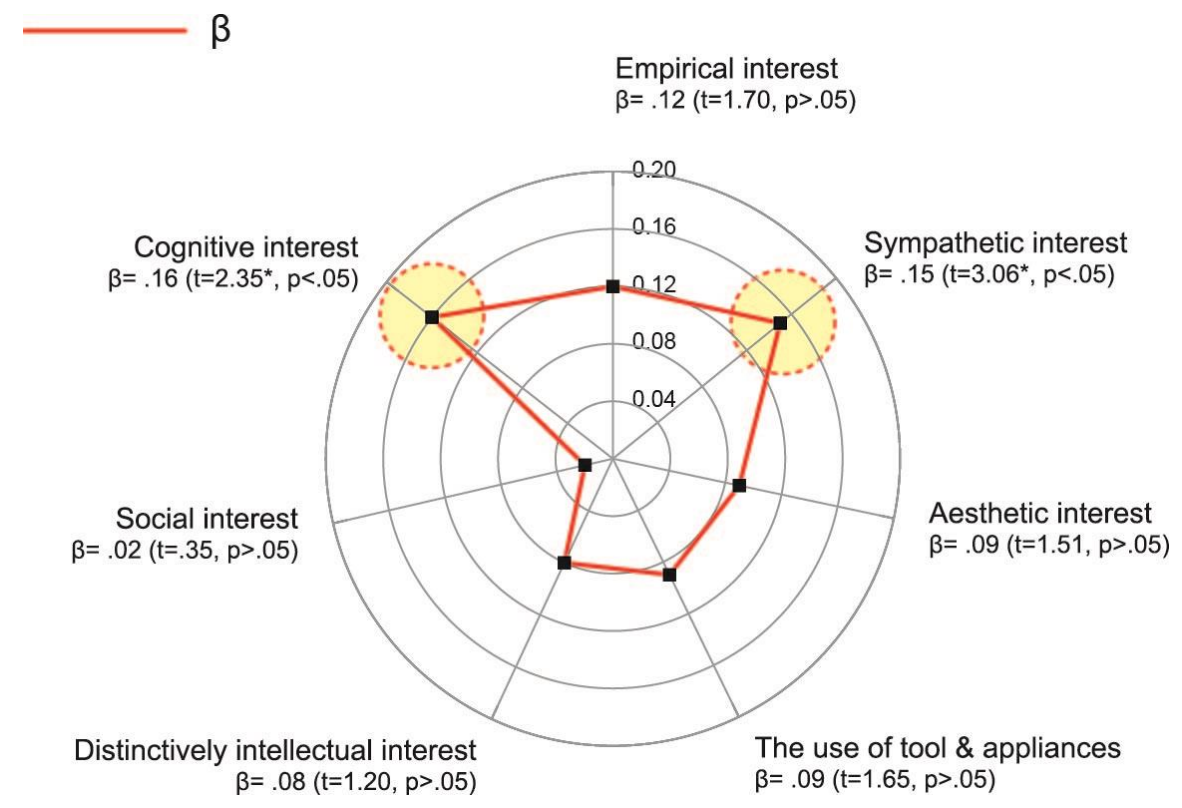

Figure 3. Influence of interest factor on relativity 


\subsection{Influence of interest factor on confidence}

Following is the result of hierarchical regression analysis on the influence of perceived interest factor on low ranked interest factor.

As the result of the analysis, confidence increases with esthetic, emphatic, cognitive and explorative factors. Experimental factor didn't show a significant influence but it has a potential possibility of being an influential factor.

Examining the individual characteristics of learners, the usage of computer and gender showed an influence. Confidence increase as the usage of computer decrease and boys showed more confidence than girls.

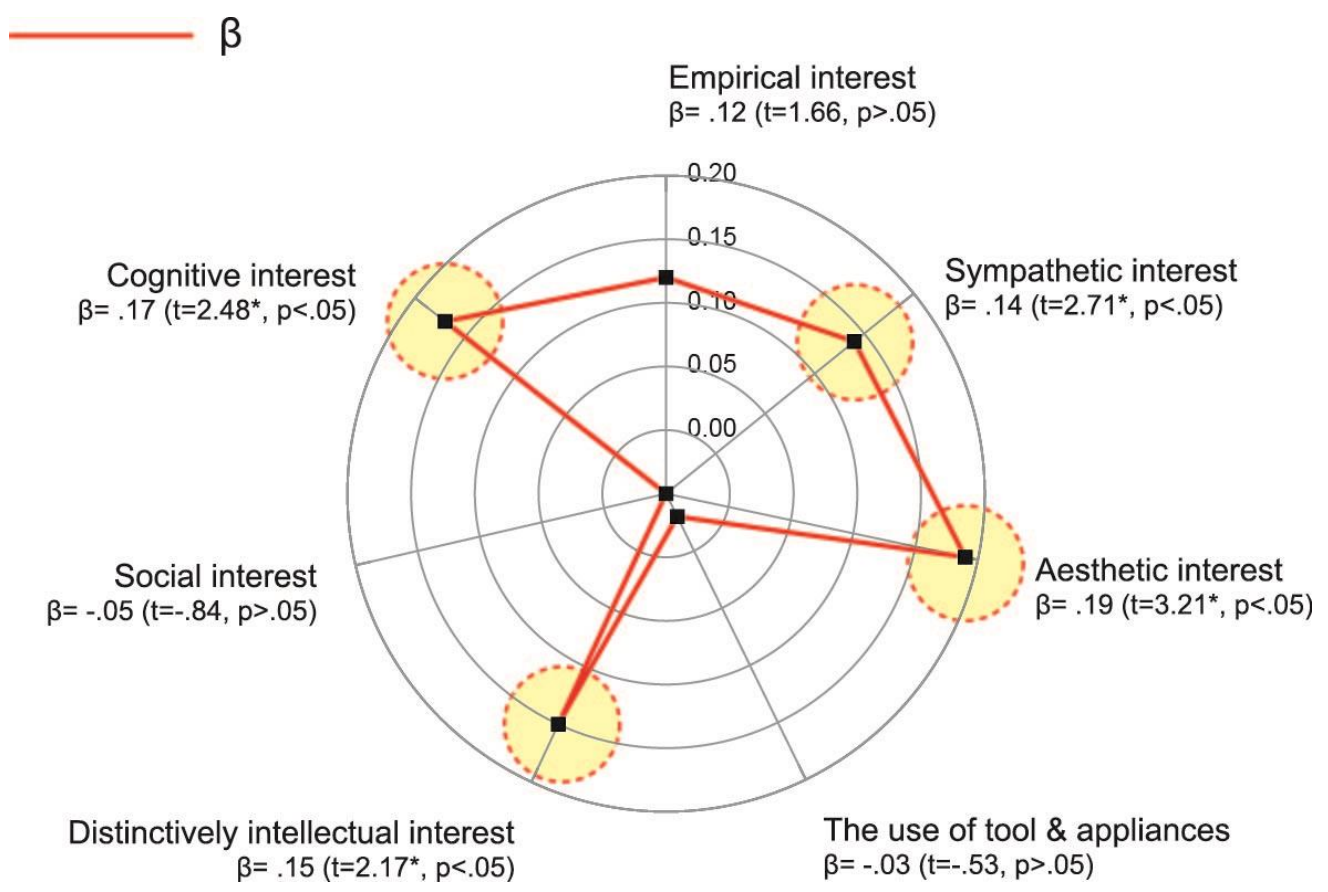

Figure 4. Influence of interest factor on confidence

\subsection{Influence of interest factor on satisfaction}

Following is the result of hierarchical regression analysis on the influence of perceived interest factor on low ranked interest factor.

Satisfaction increases with cognitive, explorative, emphatic, and esthetic factors. Examining individual characteristics of learners, satisfaction increases as the usage of computer decreases. 


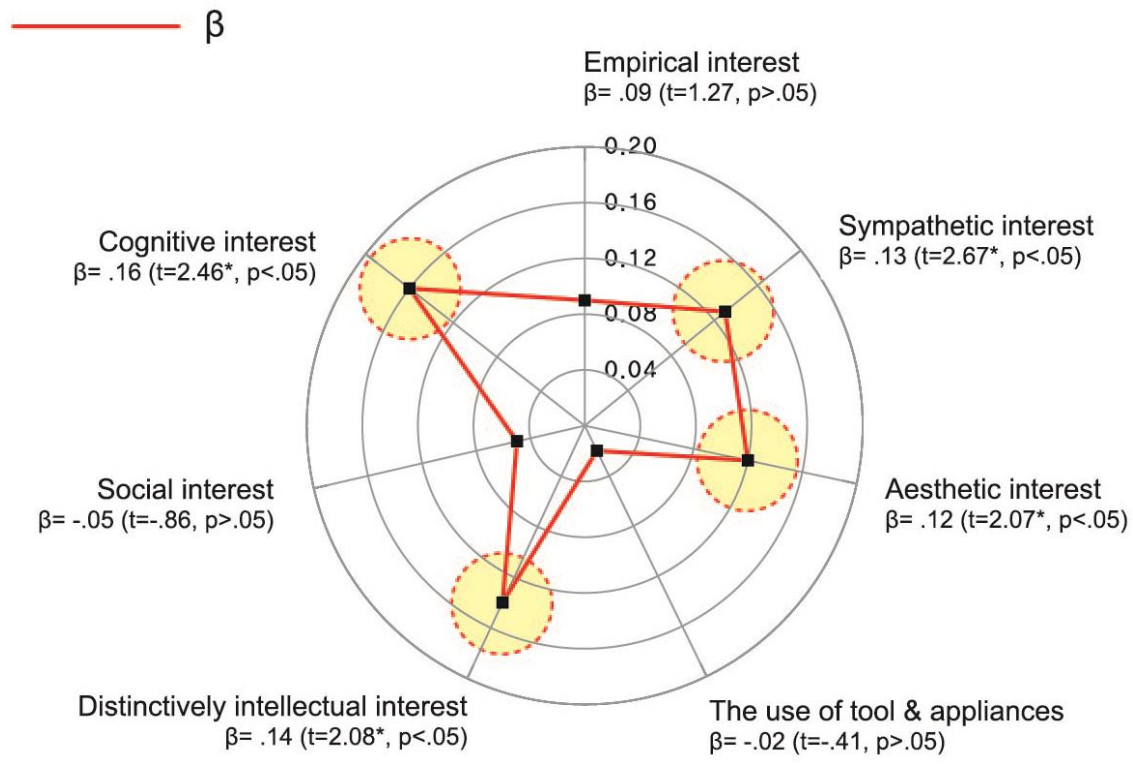

\section{Figure 5. Influence of interest factor on satisfaction}

\section{Conclusion}

The research ought to understand the influence of interest factors that the leading researches have structured. In order to examine the influence, the research accomplished a hierarchical regression analysis. As a result, it showed how the individual characteristics of learners affect learning motivation. The usage of computer, especially, showed a significant influence on motivation. As the usage of computer increase, the effectiveness of the lower ranked learning motivation such as attention, relativity, confidence and satisfaction decreased. Gender also turned out to affect the learning motivation. Boys showed more learning motivation than girls. On the other hand, junior high students showed a higher level of attention and relativity than elementary students. The emphatic factor, esthetic factor, explorative factor, and cognitive factor showed a significant influence on learning motivation. The experimental factor also showed a potential possibility of being an influential factor. Therefore, most of interest factors from the leading researches showed a positive influence on learning motivation and also an important educational source that can possibly affect the further scholastic achieve.

\section{References}

[1] K. A. Jin, "A Study onInterest Factor in Digital Textbook User Interface Design”, Korean Society of Basic Design \& Art, vol. 13, no. 2, Seoul Korea, (2012), pp. 487-495.

[2] K. A. Jin, "Factor Analysis forInterest of Digital Textbook UI Using Delphi Technique", Korean Society of Basic Design \& Art, vol. 13, no. 3, Seoul Korea, (2012), pp. 329-337.

[3] K. A. Jin, "Development of Digital Textbook UI Guideline: Focused on Percepted User Interest Experience", SPRINGER, (2012).

[4] J. F. Herbart, Allgemeine Pädagogik, Kamps Pädagogische Taschenbücher 23, H. Holstein(hrsg.) (1965).

[5] J. Dewey, "Interest andffort in Education", Kessinger Publishing, (2008). 
International Journal of Multimedia and Ubiquitous Engineering

Vol.8, No.6, (2013)

[6] J. M. Keller, "Use of the ARCS Model of Motivation in Teacher Training", IDD and E Working Paper No.10 ER I C Document Reproduction Service No. ED588520, (1983).

\section{Author}

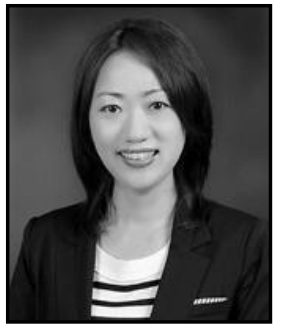

\section{Kyung A Jin}

She received the $\mathrm{PhD}$ degree in Film \& Digital Media from Hongik University in 2012, Republic of Korea. Currently, she is a professor at Department of Multimedia Design, Korea Art College. Also, She is currently researching on multimedia and digital textbook. 